The role of amine-cavity interactions in determining the structure and mechanical properties of the ferroelectric hybrid perovskite $\left[\mathrm{NH}_{3} \mathrm{NH}_{2}\right] \mathrm{Zn}(\mathrm{HCOO})_{3}$

Gregor Kieslich,* Alexander C. Forse, Shijing Sun, Keith

T. Butler, Shohei Kumagai, Yue Wu, Mark R. Warren,

Aron Walsh, Clare P. Grey and Anthony K. Cheetham*

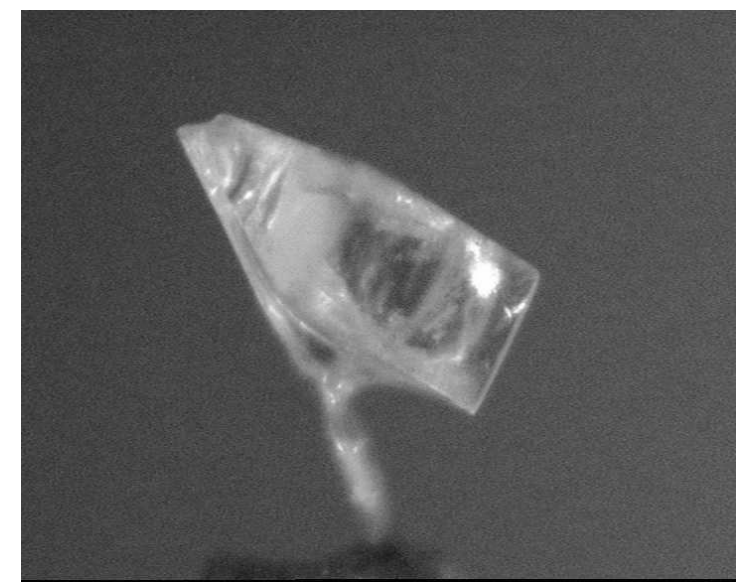

SI-Figure 1. Image of the crystal used for structure solution at $300 \mathrm{~K}$. For details of structure solution see SItable 1 and SI-table 2.

SI-Table 1. Details of structure solution and crystal data of $\left[\mathrm{NH}_{3} \mathrm{NH}_{2}\right] \mathrm{Zn}(\mathrm{HCOO})_{3}$ at $300 \mathrm{~K}$. Hydrogen atoms were located in the difference Fourier map and refined in a riding model with $\mathrm{U}_{\text {iso }}$ fixed to the riding atom. For the $\mathrm{NH}_{2}$-group, $\mathrm{N}-\mathrm{H}$ bond lengths and $\mathrm{H}-\mathrm{O}$ distances were manually to $0.890 \AA$. The obtained crystal structure is in strong agreement with the reported one by Gao et $a l$.

\begin{tabular}{|c|c|}
\hline Formula & $\mathrm{C}_{3} \mathrm{H}_{8} \mathrm{~N}_{2} \mathrm{O}_{6} \mathrm{Zn}$ \\
\hline Formula weight $(\mathrm{g} / \mathrm{mol})$ & 233.48 \\
\hline Temperature (K) & 300.00 \\
\hline Crystal system & orthorhombic \\
\hline Space group & Pna2 ${ }_{1}$ \\
\hline a $(\AA)$ & $8.66793(10)$ \\
\hline $\mathrm{b}(\AA)$ & $7.74839(8)$ \\
\hline$c(\AA)$ & $11.54775(13)$ \\
\hline$\alpha\left(^{\circ}\right)$ & 90 \\
\hline$\beta\left(^{\circ}\right)$ & 90 \\
\hline$\gamma\left(\left(^{\circ}\right)\right.$ & 90 \\
\hline Volume $\left(\AA^{3}\right)$ & $775.576(15)$ \\
\hline $\mathrm{Z} / \mathrm{Z}^{6}$ & $4 / 1$ \\
\hline$\rho_{\text {calc }}\left(\mathrm{g} \mathrm{cm}^{-3}\right)$ & 2.000 \\
\hline$\mu\left(\mathrm{mm}^{-1}\right)$ & 3.163 \\
\hline $\mathrm{F}(000)$ & 472 \\
\hline
\end{tabular}

\begin{tabular}{|c|c|}
\hline Crystal size $\left(\mathrm{mm}^{3}\right)$ & $0.5086 \times 0.4241 \times 0.3235$ \\
\hline Radiation & $\operatorname{MoK}_{\alpha}(\lambda=0.71073)$ \\
\hline $\begin{array}{l}2 \Theta \text { range for data } \\
\text { collection }\left(^{\circ}\right)\end{array}$ & 3.526 to 74.832 \\
\hline Index ranges & $\begin{array}{r}-14 \leq \mathrm{h} \leq 14 \\
-13 \leq \mathrm{k} \leq 13 \\
-19 \leq 1 \leq 19\end{array}$ \\
\hline Reflections collected & 61402 \\
\hline Independent reflections & $\begin{array}{r}3996\left[\mathrm{R}_{\mathrm{int}}=0.0293, \mathrm{R}_{\text {sigma }}\right. \\
=0.0127]\end{array}$ \\
\hline Data/restraints/parameters & $3996 / 6 / 118$ \\
\hline Goodness-of-fit on $\mathrm{F}^{2}$ & 1.069 \\
\hline $\begin{array}{l}\text { Final } R \text { indexes }[\mathrm{I}>=2 \sigma \\
\text { (I)] }\end{array}$ & $\begin{array}{r}\mathrm{R}_{1}=0.0188, w \mathrm{R}_{2}= \\
0.0434\end{array}$ \\
\hline Final $\mathrm{R}$ indexes [all data] & $\begin{array}{r}\mathrm{R}_{1}=0.0256, \mathrm{wR}_{2}= \\
0.0455\end{array}$ \\
\hline $\begin{array}{l}\text { Largest diff. peak/hole / ( } \\
\left.\AA^{-3}\right)\end{array}$ & $0.39 /-0.31$ \\
\hline Flack parameter & $-0.004(3)$ \\
\hline Extinction coefficient & $0.0150(8)$ \\
\hline
\end{tabular}

SI-Table 2. Fractional atomic coordinates $\left(\mathrm{x} 10^{4}\right)$ and equivalent isotropic displacement parameters $\left(\AA^{2} \times 10^{3}\right)$ of the hybrid perovskite $\left[\mathrm{NH}_{3} \mathrm{NH}_{2}\right] \mathrm{Zn}(\mathrm{HCOO})_{3}$ at $300 \mathrm{~K}$.

\begin{tabular}{cllll} 
Atom & \multicolumn{1}{c}{$\boldsymbol{x}$} & \multicolumn{1}{c}{$\boldsymbol{y}$} & \multicolumn{1}{c}{$\boldsymbol{z}$} & \multicolumn{1}{c}{$\mathbf{U}(\mathbf{e q})$} \\
Zn1 & $4748.9(2)$ & $5000.6(2)$ & $4482.9(5)$ & $15.14(4)$ \\
C7 & $5288(2)$ & $5618.9(19)$ & $6983.1(18)$ & $22.0(3)$ \\
C8 & $2458(2)$ & $7774(2)$ & $4095.9(16)$ & $24.4(3)$ \\
C9 & $6930(2)$ & $2104(2)$ & $4770.8(14)$ & $23.8(3)$ \\
O1 & $5143.2(17)$ & $6349.6(17)$ & $6033.4(11)$ & $26.9(3)$ \\
O2 & $4475.4(16)$ & $3610.8(16)$ & $2926.8(10)$ & $22.9(2)$ \\
O3 & $5729.3(15)$ & $2739.6(15)$ & $5172.8(11)$ & $24.5(2)$ \\
O4 & $3785.0(14)$ & $7283.0(15)$ & $3817.1(11)$ & $23.6(2)$ \\
O5 & $6896.2(13)$ & $5806.4(15)$ & $3835.9(12)$ & $24.7(2)$ \\
O6 & $2625.9(13)$ & $4167.9(14)$ & $5186.5(11)$ & $23.1(2)$ \\
N2 & $4130(4)$ & $10093(2)$ & $6681(3)$ & $46.4(8)$ \\
N3 & $5645(3)$ & $9928.4(18)$ & $7143(2)$ & $30.6(5)$ \\
H7 & 5218 & 4421 & 6999 & 26 \\
H8 & 1853 & 7021 & 4528 & 29 \\
H9 & 7344 & 2612 & 4110 & 29 \\
H3A & 6334 & 10071 & 6580 & 37 \\
H3B & 5758 & 8884 & 7453 & 37 \\
H3C & 5792 & 10727 & 7687 & 37 \\
H2A & $4070(9)$ & $11030(11)$ & $6238(12)$ & 46 \\
H2B & $3897(9)$ & $9165(10)$ & $6261(12)$ & 46
\end{tabular}

\section{Electron Localization Function}

As mentioned in the main text, the Electron Localization Function allows for analyzing chemical bonding from a more fundamental point of view. ${ }^{1,2}$ Simply speaking, the ELF provides a method for mapping the electron pair probability in direct space, allowing an analysis of the types of chemical bonding, such as covalent interactions, lone pairs, atomic shells etc. in a chemically intuitive way. In SI-Figure 2, the ELF of $\left[\mathrm{NH}_{3} \mathrm{NH}_{2}\right] \mathrm{Zn}(\mathrm{HCOO})_{3}$ is plotted with different values of the $f$-localization domain, $f$ $=0.80$ (a), $f=0.85$ (b) and $f=0.90(\mathbf{c})$. The dominant maxima in the ELF, SI-Figure 2c, corresponds to the N-H bonds in hydrazinium cation and $\mathrm{C}-\mathrm{H}$ bonds within the 
formate linker. For smaller values of $f$ (Figure $2 \mathrm{~b}$ and $2 \mathrm{a}$ ), e.g. $f=0.85$, a maximum of the ELF is observed between oxygen and carbon atoms, which corresponds to the covalent O-C-O interaction within the formate linker. The carbon-oxygen bond lengths are similar to bond lengths observed in other formate compounds, e.g. $\alpha-\mathrm{Mg}(\mathrm{HCOO})_{3}$ and $\mathrm{NaHCOO}$, and are consistent with a delocalized $\pi$ system. ${ }^{3}$ Within the hydrazinium cation, the nitrogennitrogen bond length is $1.42 \AA$ and slightly shorter than in the pure $\mathrm{NH}_{2} \mathrm{NH}_{3} \mathrm{Cl}$ with $1.45 \AA .{ }^{4}$ The corresponding maximum in the ELF can be observed in Figure 2a and $b$. The coordinative zinc-oxygen bond has a maximum in the ELF, visible in Figure 1(b). Zinc-oxygen bond lengths are between $2.099 \AA$ and $2.114 \AA$ and are typical values for zinc based formate frameworks. ${ }^{5,6}$

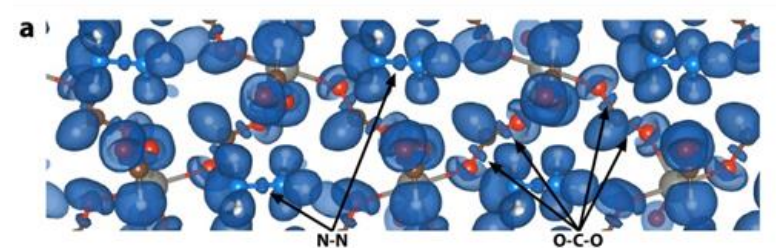

b
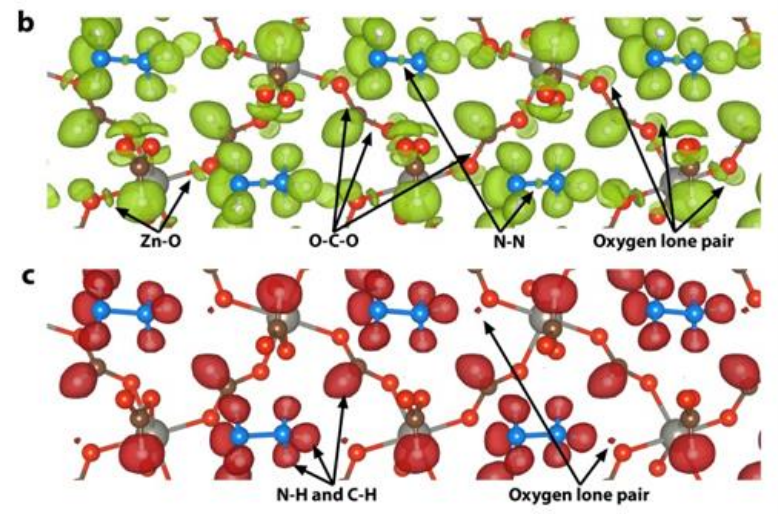

SI-Figure 2. Electron Localisation Function (ELF) of $\left.\left[\mathrm{NH}_{3} \mathrm{NH}_{2}\right)\right] \mathrm{Zn}(\mathrm{HCOO})_{3}$ shown with an isosurface level $f=$ $0.80(\mathbf{a}), f=0.85$ (b) and $f=0.90(\mathbf{c}) . f$ corresponds to the so-called f-localization domain and for a given value $\mathrm{f}=$ $\mathrm{x}$, the f-localization domain contains all points where ELF takes values larger than $\mathrm{x}(\mathrm{ELF}>f)$. Simply speaking, the ELF provides a method for mapping of the electron pair probability and analysing bonding interactions in a chemical intuitive way. As highlighted in the figure, this helps to visualize covalent interactions within the formate linker and hydrazinium cation, (a) and (b) and lone pairs located at oxygen atoms, (b) and (c). The lone pairs located at the oxygen atoms are particularly important for amine-cavity interactions in this framework.
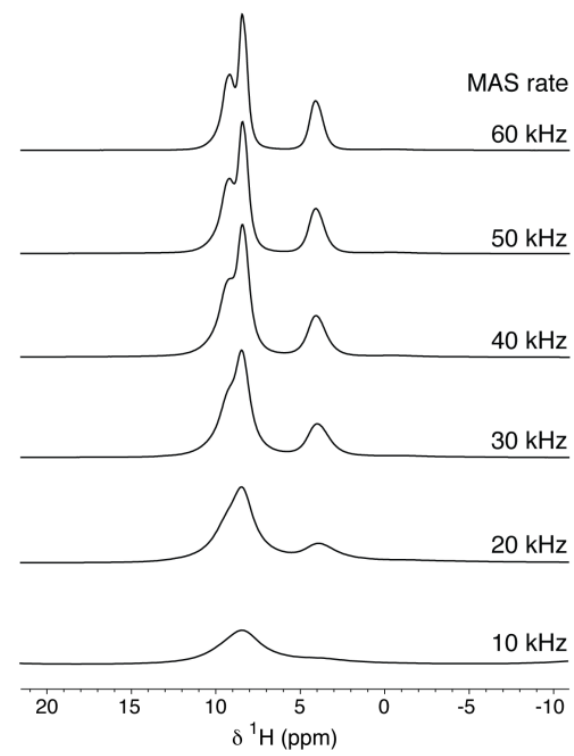

SI-Figure 3. Plotted are the ${ }^{1} \mathrm{H}$ MAS NMR spectra in dependence of the applied MAS rate. A spinning frequency of $60 \mathrm{kHz}$ is necessary to be able to distinguish between the different proton sites in $\left[\mathrm{NH}_{3} \mathrm{NH}_{2}\right] \mathrm{Zn}(\mathrm{HCOO})_{3}$.
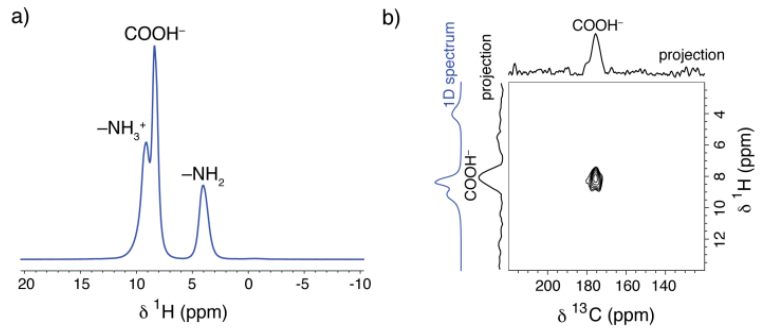

SI-Figure 4. ${ }^{1} \mathrm{H}$ MAS NMR (11.8 $\left.\mathrm{T}\right)$ spectrum of $\left[\mathrm{NH}_{3} \mathrm{NH}_{3}\right] \mathrm{Zn}(\mathrm{HCOO})_{3}$, recorded with an MAS rate of 60 $\mathrm{kHz}$ (a) and (b) 2D HETCOR experiment recorded with an MAS rate of $50 \mathrm{kHz}$, and a contact time of $100 \mu \mathrm{s}$ for cross polarisation from ${ }^{1} \mathrm{H}$ to ${ }^{13} \mathrm{C}$. Three different chemical environments can be distinguished arising from the $\mathrm{HCOO}, \mathrm{NH}_{3}$ and $\mathrm{NH}_{2}$ groups. 


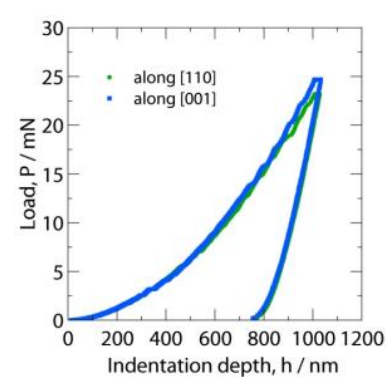

SI-Figure 5. Typical Load-displacement curve of a nanoindentation experiment of $\left[\mathrm{NH}_{3} \mathrm{NH}_{2}\right] \mathrm{Zn}(\mathrm{HCOO})_{3}$. Edges in the curve correspond to so-called 'pop-in' events, that are observed oftentimes for such frameworks. $^{7,8}$

\section{Methods}

Electron Localization Function. Prior to calculations of the Electron Localization Funtion of $\left[\mathrm{NH}_{3} \mathrm{NH}_{2}\right] \mathrm{Zn}(\mathrm{HCOO})_{3}$, electronic structure calculations were performed using the VASP package , ${ }^{9}$ within the projector augmented wave (PAW) pseudo-potential formalism. ${ }^{10}$ Energies and forces were calculated using the PBESol functional ${ }^{11}$ with a plane wave basis set up to a cutoff of $500 \mathrm{eV}$. A k-point mesh was chosen to ensure a sampling of reciprocal space of at least $0.04 \mathrm{k}$-points in accordance with the prescribed density for semiconductors .$^{12}$ Electron localisation functions (ELF) ${ }^{13}$ were calculated to investigate bonding patterns, in this case an extended representation of the electron density, including semi-core states of $\mathrm{Zn}$ was applied.

Synthesis of $\left[\mathrm{NH}_{3} \mathbf{N H}_{2}\right] \mathrm{Zn}(\mathrm{HCOO})_{3}$. Single crystals of $\left[\mathrm{NH}_{3} \mathrm{NH}_{2}\right] \mathrm{Zn}(\mathrm{HCOO})_{3}$ were grown using the mild solution approach reported by Gao et al. ${ }^{14}$ In a typical synthesis, $1 \mathrm{mmol}$ of $\mathrm{Zn}\left(\mathrm{ClO}_{4}\right)_{2} \cdot 6 \mathrm{H}_{2} \mathrm{O}$ was dissolved in a mixture of $4 \mathrm{ml}$ of $\mathrm{MeOH}$. In another beaker, $40 \mathrm{mmol}$ of $\mathrm{HCOOH}$ and $6 \mathrm{mmol}$ of aequos solution of $85 \%$ hydrazine were dissolved in $5 \mathrm{ml} \mathrm{MeOH}$. The two solutions were mixed together and kept at room temperature. After several days, transparent, colorless crystals (SI-Figure 1) were collected and analysed.

X-ray diffraction. Single crystal diffraction experiments were carried out using an Oxford Diffraction Gemini A Ultra X-ray diffractometer with $\mathrm{Mo} \mathrm{K}_{\alpha}$ radiation $(\lambda=$ $0.70930 \AA$ ) operated at $50 \mathrm{kV}$ and $40 \mathrm{~mA}$. Data were collected at $300 \mathrm{~K}$. Data collection, unit cell determination and refinement, absorption correction and data reduction were performed using the CrysAlisPro software from Agilent Technologies. The structures were solved by direct methods and were then refined by the least squares methods using the SHELX ${ }^{15}$ program within the Olex $2^{16}$ interface. All non-hydrogen atoms were refined anisotropically and hydrogen atoms were refined isotropically. Hydrogen atoms were added to chemically reasonable positions found in the Fourier difference map, and then refined with constrained $\mathrm{N}-\mathrm{H}$ distances $(0.890$ $\AA$ ). After structure solution, an analytical absorption correction was performed by applying a face-based absorption correction. Details of structure solution are available in the supporting information, SI-Table 1 and 2.

${ }^{1} \mathrm{H}$ NMR experiments and structure optimization. NMR experiments were performed using a Bruker Avance III spectrometer operating at magnetic field strengths of $11.7 \mathrm{~T}$, corresponding to a ${ }^{1} \mathrm{H}$ Larmor frequency of 500 MHz. A Bruker $1.3 \mathrm{~mm}$ magic angle spinning (MAS) double resonance probe was used for all experiments, and the sample was packed as a finely ground powder. For direct excitation experiments, the MAS rate was $60 \mathrm{kHz}$ and a spin-echo sequence was used, with a single rotor period $(16.67 \mu \mathrm{s})$ used as the spin-echo delay. The recycle delay of $6 \mathrm{~s}$ was found to give quantitative spectra, the pulse power was $109 \mathrm{kHz}$, and 32 transients were coadded to produce the final signal before Fourier transformation. For the two-dimensional HETCOR experiment, the MAS rate was $50 \mathrm{kHz}$, and a contact time of $100 \mu \mathrm{s}$ was used to select for the short-range formate $\mathrm{C}-\mathrm{H}$ correlation. Here a recycle delay of $2 \mathrm{~s}$ was used and the 248 transients were co-added for each row. $1 \mathrm{H}$ and 13C spectra were referenced relative to adamantane at $\left({ }^{1} \mathrm{H}\right.$ : $1.8 \mathrm{ppm}, 13 \mathrm{C}$ : $38.5 \mathrm{ppm}$; tertiary carbon atom). Spectral fits were carried out using the SOLA package in Topspin software. A single peak was used to fit the $\mathrm{NH}_{2}$ and $\mathrm{NH}_{3}$ environments, and two peaks were required to fit the signal from the formate groups.

NMR calculations were performed using the CASTEP DFT code, ${ }^{17}$ using the gauge including projector augmented wave (GIPAW) approach. ${ }^{18}$ The PBE (with a generalised gradient approximation) functional was used for the exchange-correlation term, ${ }^{19}$ and ultrasoft psuedopotentials were used. ${ }^{20}$ Calculations used planewave basis functions with an energy cut-off of 70 Ry. A k-point spacing of $0.03 \AA-1$ was used. Calculated chemical shifts, $\sigma$ iso, were obtained using; $\sigma_{\text {iso }}=-\left(\sigma_{\text {iso }}-\right.$ $\sigma_{\text {ref }}$ ), where $\sigma_{\text {iso }}$ is the calculated isotropic shielding, and $\sigma_{\text {ref }}$ is a reference value. For ${ }^{1} \mathrm{H}$ spectra, a $\sigma_{\text {ref }}$ value of 30.5 ppm was used, as in previous studies at the same level of theory. ${ }^{21,22}$ NMR calculations were performed on two structures, the structure obtained from single crystal X-ray diffraction data, and the structure obtained following geometry optimisation in CASTEP. For the geometry optimisation, the unit cell parameters were fixed, while the positions of the atoms were allowed to vary.

Nanoindentation. Prior to nanoindentation experiments, single crystals of $\left[\mathrm{NH}_{3} \mathrm{NH}_{2}\right] \mathrm{Zn}(\mathrm{HCOO})_{3}$ were faceindexed using single crystal X-ray diffraction (Mo radiation) at room temperature. In a next step, the crystals were glued onto aluminum chips with [001] or [110] directions normal to the aluminum chip. Samples were 
cold mounted in Epofix resion (Struers Ltd.), following by grinding and polishing to remove the aluminium chips and minimise surface roughness, respectively, as previously reported in literature. ${ }^{7,23}$

Nanoindentation experiments were performed with a MTS Nanoindenter XP located in an isolation cabinet, minimizing thermal instability and acoustic interference at room temperature. Calibration was done using a fused silica standard (elastic modulus of $72 \mathrm{GPa}$, hardness of 9 $\mathrm{GPa}$ ). The indenter was aligned normal to [001] or [110] and a minimum of 20 indentations were carried out on each sample using a three-sided pyramidal Berkovich tip (radius approx. $100 \mathrm{~nm}$ ). A dynamic displacement controlled continuous stiffness measurement (CSM) mode was applied, with a sinusoidal displacement $(2 \mathrm{~nm})$ at a frequency of $45 \mathrm{~Hz}$ superimposed on to primary loading curves, until reaching maximum indentation depth of 1000 $\mathrm{nm}$. Elastic modulus (E) and indentation hardness $(\mathrm{H})$ were hence deduced using the Oliver and Pharr method. ${ }^{24}$

High pressure single crystal diffraction. High pressure single crystal diffraction data was collected at Diamond Lightsource, beamline I19 (experiment MT10184). For experiments, crystals were loaded into Diamond Anvil Cells using Fluorinert70 as pressure medium. Single cystal diffraction was then performed using monochromatic, $\lambda=0.68890 \AA$. Analogues to lab X-ray diffraction, data reduction was performed using CrysAlisPro software from Agilent technologies .

\section{REFERENCES}

(1) Becke, A. D.; Edgecombe, K. E. A simple measure of electron localization in atomic and molecular systems. $J$. Chem. Phys. 1990, 92, 5397.

(2) Grin, Y.; Savin, A.; Silvi, B. In The Chemical Bond. Frenking, Gernot, Shaik, Sason, Eds.; Wiley-VCH Verlag GmbH \& Co. KGaA: Weinheim, Germany, 2014.

(3) Zachariasen, W. H. The Crystal Structure of Sodium Formate, $\mathrm{NaHCO}_{2}$. J. Am. Chem. Soc. 1940, 62, 10111013.

(4) Sakurai, K.; Tomiie, Y. The crystal structure of hydrazinium chloride, $\mathrm{N}_{2} \mathrm{H}_{5} \mathrm{Cl}$. Acta Cryst. 1952, 5, 293294.

(5) Clausen, H. F.; Poulsen, R. D.; Bond, A. D.; Chevallier, M.-A. S.; Iversen, B. B. Solvothermal synthesis of new metal organic framework structures in the zinc-terephthalic acid-dimethyl formamide system. $J$. Solid State. Chem. 2005, 178, 3342-3351.

(6) Hu, K.-L.; Kurmoo, M.; Wang, Z.; Gao, S. Chem. Eur. J. 2009, 15, 12050-12064.

(7) Tan, J.; Merrill, C.; Orton, J.; Cheetham, A. Anisotropic mechanical properties of polymorphic hybrid inorganic-organic framework materials with different dimensionalities. Acta Materialia. 2009, 57, 3481-3496.

(8) Tan, J.-C.; Jain, P.; Cheetham, A. K. Influence of ligand field stabilization energy on the elastic properties of multiferroic MOFs with the perovskite architecture. Dalton Trans. 2012, 41, 3949.

(9) Kresse, G.; Furthmüller, J. Efficient iterative schemes for ab initio total-energy calculations using a plane-wave basis set. Phys. Rev. B. 1996, 54, 11169-11186.
(10) Blöchl, P. E. Projector augmented-wave method. Phys. Rev. B. 1994, 50, 17953-17979.

(11) Perdew, J. P.; Ruzsinszky, A.; Csonka, G. I.; Vydrov, O. A.; Scuseria, G. E.; Constantin, L. A.; Zhou, X.; Burke, K. Restoring the Density-Gradient Expansion for Exchange in Solids and Surfaces. Phys. Rev. Lett. 2008, 100.

(12) Moreno, J.; Soler, J. M. Optimal meshes for integrals in real- and reciprocal-space unit cells. Phys. Rev. B. 1992, 45, 13891-13898.

(13) Silvi, B.; Savin, A. Classification of chemical bonds based on topological analysis of electron localization functions. Nature. 1994, 371, 683-686.

(14) Chen, S.; Shang, R.; Hu, K.-L.; Wang, Z.-M.; Gao, S. $\left[\mathrm{NH}_{2} \mathrm{NH}_{3}\right]\left[\mathrm{M}(\mathrm{HCOO})_{3}\right]\left(\mathrm{M}=\mathrm{Mn}^{2+}, \mathrm{Zn}^{2+}, \mathrm{Co}^{2+}\right.$ and $\mathrm{Mg}^{2+}$. Inorg. Chem. Front. 2014, 1, 83-98.

(15) Sheldrick, G. M. A short history of SHELX. Acta Cryst. A 2008, 64, 112-122.

(16) Dolomanov, O. V.; Bourhis, L. J.; Gildea, R. J.; Howard, J. A. K.; Puschmann, H. OLEX2. J. Appl. Crystallogr. 2009, 42, 339-341.

(17) Clark, S. J.; Segall, M. D.; Pickard, C. J.; Hasnip, P. J.; Probert, M. I. J.; Refson, K.; Payne, M. C. First principles methods using CASTEP. Z. Kristallogr. 2005, 220.

(18) Pickard, C. J.; Mauri, F. All-electron magnetic response with pseudopotentials: NMR chemical shifts. Phys. Rev. B. 2001, 63.

(19) Perdew, J. P.; Burke, K.; Ernzerhof, M. Generalized Gradient Approximation Made Simple. Phys. Rev. Lett. 1996, 77, 3865-3868.

(20) Yates, J. R.; Pickard, C. J.; Mauri, F. Calculation of NMR chemical shifts for extended systems using ultrasoft pseudopotentials. Phys. Rev. B. 2007, 76.

(21) Griffin, J. M.; Berry, A. J.; Ashbrook, S. E. Observation of "hidden" magnesium: First-principles calculations and $25 \mathrm{Mg}$ solid-state NMR of enstatite. Solid State Nucl. Mag. 2011, 40, 91-99.

(22) Kim, G.; Griffin, J. M.; Blanc, F.; Haile, S. M.; Grey, C. P. Characterization of the Dynamics in the Protonic Conductor $\mathrm{CsH}_{2} \mathrm{PO}_{4} \quad$ by ${ }^{17} \mathrm{O}$ Solid-State NMR Spectroscopy and First-Principles Calculations: correlating Phosphate and Protonic Motion. J. Am. Chem. Soc. 2015, 137, 3867-3876.

(23) Henke, S.; Li, W.; Cheetham, A. K. Guest-dependent mechanical anisotropy in pillared-layered soft porous crystals - a nanoindentation study. Chem. Sci. 2014, 5, 2392.

(24) Oliver, W.; Pharr, G. Measurement of hardness and elastic modulus by instrumented indentation: Advances in understanding and refinements to methodology. J. Mater. Res. 2004, 19, 3-20. 